\title{
MEJORA DE LA REGULACIÓN EN LA ECONOMÍA COLABORATIVA. EL CASO DE LAS VIVIENDAS TURÍSTICAS EN ANDALUCÍA
}

Better regulation in Collaborative Economics. The case of tourist housing in Andalusia

\author{
JOSÉ FÉLIX RISCOS GÓMEZ ${ }^{1}$ \\ Agencia de Defensa de la Competencia de Andalucía. \\ JOSÉ LUIS GARCÍA HIDALGO ${ }^{2}$. \\ Departamento de Análisis Económico y Economía Política. Cátedra de Política de \\ Competencia, Universidad de Sevilla \\ LUIS PALMA MARTOS ${ }^{3}$ \\ Departamento de Economía e Historia Económica. Cátedra de Política de \\ Competencia, Universidad de Sevilla. Agencia de Defensa de la Competencia de \\ Andalucía.
}

\begin{abstract}
Resumen: El mercado del alojamiento colaborativo está experimentando un fuerte crecimiento en los últimos años. Esto supone, por un lado, una oportunidad para el estimular el crecimiento económico y el empleo en un sector estratégico como el turismo; pero, por otro, plantea importantes retos en materia de regulación, que se antojan claves para aprovechar los beneficios de esta nueva economía. El presente estudio reflexiona sobre esta cuestión para identificar los elementos propios de la buena regulación económica en el mercado del alojamiento turístico, a partir del estudio de las tentativas reguladoras de los órganos autonómicos, prestando especial atención al caso de Andalucía, por ser la experiencia de mayor éxito en este ámbito.
\end{abstract}

Palabras claves: Economía colaborativa, mejora de la regulación económica, viviendas con fines turísticos, competencia.

Abstract: The collaborative hosting market is seeing strong growth in recent years. This means, on the one hand, an opportunity to stimulate economic growth and employment in a strategic sector such as tourism; but, on the other hand, it raises important regulatory challenges that seem like keys to take advantage of the benefits of this new economy. The present study reflects on this issue in order to identify the elements of better regulation in the tourist hosting market based on a study of the regulatory attempts of the autonomic regulatory bodies, paying particular attention to the case of Andalusia, as it is the most successful experience in this area.

Keywords: Collaborative economics, better regulation, tourist housing, competition.

\footnotetext{
${ }^{1}$ Jfelix.riscos@juntadeandalucia.es.

2jgarcia16@us.es.

3 1palma@us.es.
} 


\section{Introducción.}

Los mercados circunscritos al ámbito de la economía colaborativa están experimentando un crecimiento exponencial en los últimos años ${ }^{4}$. Las posibilidades que brinda la interconexión en tiempo real de los individuos de una sociedad, facilitada por la difusión de los teléfonos inteligentes o smartphones, son todavía un enigma. Lo que sí parece claro es que este nuevo escenario interpela al proceso de producción y consumo característico de un sistema capitalista que desde hace décadas muestra síntomas de una preocupante madurez.

Dada la dimensión que está adquiriendo el mencionado fenómeno, muchos han sido los trabajos e investigaciones sobre el particular en los últimos años. El trabajo de Botsman y Rogers (2010), titulado "What's is mine is yours: The rise of collaborative consumption", puede considerarse el punto de partida. A partir de ese momento, muchos de los conceptos propios de la economía colaborativa empezaron a desarrollarse en otros trabajos de interés, tales como, Belk (2010), Bardhi y Eckhardt (2012), Stoke, et al. (2014), Rifkin (2014), Koopman et al. (2015) o Codagnone y Martens (2016), todos ellos dedicados al consumo colaborativo. Muchos de estos autores vaticinan que la economía colaborativa ha llegado para cambiar el paradigma económico actual, interpelando a conceptos tradicionalmente nucleares de la economía tradicional tales como el empleo.

Por otro lado, entre las investigaciones dedicadas al análisis económico de la economía colaborativa podemos destacar las de Oxera (2015), y Evans y Schamalensee (2016). En ellas se pone el acento en las ganancias de eficiencia que conllevan los mercados colaborativos, además de identificar algunos de sus efectos adversos.

Asimismo, sobre las características propias del mercado del alojamiento colaborativo podemos encontrar los trabajos de Franch Fluxá y Ribas Conrado (2013), Jefferson-Jones (2016), Oskam y Boswijk (2016) y Guillén Navarro e Íñiguez Barrozpe (2016).

Por último, trabajos dedicados a la regulación de la economía colaborativa podemos encontrar los trabajos de Cohen y Sundararahan (2015), Katz (2015), Gerardin (2015), Edelman y Gerardin (2016), Lougher y Kalmanowicz (2016), Smorto (2016) y Montero Pascual (2017). Dichos trabajos están mayoritariamente orientados a identificar, desde un punto teórico y con una metodología lógico deductiva, las características propias que deben incorporar los marcos regulatorios que ordenen los mercados colaborativos.

Sin embargo, la economía colaborativa se encuentra en pleno proceso de desarrollo, lo que obliga a interpretar los resultados de dichas investigaciones con prudencia. Hasta que el fenómeno no se asiente y reduzca las hiperbólicas tasas de crecimiento que viene registrando en los últimos años, no podremos estudiar y comprender este nuevo paradigma en toda su dimensión y complejidad.

El presente trabajo está dedicado al análisis de uno de los sectores más relevantes de la economía colaborativa: el alojamiento turístico. El objetivo general de la investigación es identificar los elementos propios de la buena regulación económica en el mercado de las viviendas con fines turísticos (en adelante, VFT). Para ello, tomaremos como referencia el

\footnotetext{
${ }^{4}$ Según un estudio de PwC (2016), la economía colaborativa en 2015 generó ingresos en Europa por valor de 4.000 millones de euros, con unos efectos inducidos estimados en 28.000 millones de euros. El mismo estudio proyecta unos ingresos y unos efectos inducidos de 80.000 y 570.000 millones de euros, respectivamente.
} 
Decreto 28/2016, de 2 de febrero, de las viviendas con fines turísticos y de modificación del Decreto 194/2010, de 20 de abril, de establecimientos de apartamentos turísticos de Andalucía, ya que se trata de la única normativa autonómica sobre el particular que no ha sido recurrida ante los tribunales.

Otros objetivos específicos, vinculados al general, pasan por reflexionar en torno a las características sustanciales del emergente modelo del alojamiento colaborativo. Además, se recogen las orientaciones europeas para la regulación de la economía colaborativa en particular y de las VFT en general.

El texto establece el marco teórico de la economía colaborativa (epígrafe 2), donde se destacan tanto los beneficios potenciales como los posibles riesgos que entraña el paradigma colaborativo. Asimismo, se incluyen algunas reflexiones sobre la economía colaborativa desde la perspectiva del análisis económico. La tercera sección versa sobre los retos de regulación que la economía colaborativa debe afrontar, así como el modo en que las autoridades de competencia se ven interpeladas por el desarrollo de los mercados colaborativos.

El cuarto epígrafe está dedicado ya al alojamiento colaborativo. Se trata de comprender las características sustanciales del mercado en cuestión, antes de presentar la visión de las instituciones europeas y de las autoridades de competencia sobre la regulación de la economía colaborativa en general, y del alojamiento colaborativo en particular.

En la quinta sección descendemos a lo concreto, para presentar un estudio comparativo de distintas tentativas impulsadas por gobiernos autonómicos del Estado español para abordar la regulación de las VFT. Los intentos frustrados de muchas Comunidades Autónomas contrastan con lo sucedido en Andalucía, donde la regulación del alojamiento colaborativo (vigente desde febrero de 2016), ni ha sido recurrida en los tribunales, ni está restringiendo el desarrollo de este mercado, estableciendo un level playing field entre los incumbentes y los nuevos entrantes.

Precisamente, las conclusiones de esta investigación y la aportación que pretende ofrecer consisten en identificar los elementos en materia de regulación que fomentan las virtudes del turismo colaborativo y minimizan las posibles consecuencias negativas para los intereses generales, de la eclosión y crecimiento exponencial del mercado de las VFT, a partir de la evidencia empírica encarnada en los recursos de la CNMC contra otras regulaciones autonómicas. El artículo finaliza con un apartado de fuentes bibliográficas.

\subsection{Metodología}

Para alcanzar los objetivos planteados se ha seguido una metodología consistente en, por un lado, la revisión sistemática de la bibliografía sobre el particular, procurando abarcar trabajos de los autores más relevantes en la materia, así como de la documentación que emana de organismos oficiales como la UE.

Por otro lado, se ha aplicado el análisis económico para analizar tanto la economía colaborativa en general como el mercado del alojamiento colaborativo en particular. Dicho análisis también se ha apoyado en la literatura existente.

Finalmente, se ha realizado un estudio comparativo sobre los marcos reguladores que han tratado de configurarse en otras comunidades autónomas para comprender los motivos por los que no han resultado satisfactorios en la mayoría de los casos, con la excepción de Andalucía. Para ello, se han revisado sistemáticamente los informes sobre el particular 
realizados por la Comisión Nacional de los Mercados y la Competencia (en adelante, CNMC) en los que se ponía el acento en las restricciones a la competencia y la protección de los incumbentes en los proyectos regulatorios autonómicos. En definitiva, se trata de entender las virtudes del marco normativo andaluz no a partir del análisis deductivo, como suelen hacer los trabajos dedicados a la regulación de la economía colaborativa, sino a partir de la evidencia empírica, encarnada en los informes de la CNMC.

\section{La economía colaborativa como nuevo paradigma económico.}

La economía colaborativa es un fenómeno parcialmente novedoso. Decimos parcialmente porque, desde que existe la sociedad y las relaciones económicas, los seres humanos han recurrido a ella para satisfacer sus necesidades. Es más, antes de que el mercado alcanzase el grado de madurez actual, las relaciones económicas colaborativas eran recurrentes. $^{5}$

Lo realmente novedoso de la economía colaborativa es la dimensión que está adquiriendo en la actualidad, fruto de dos fenómenos principalmente:

a) El desarrollo y universalización de las nuevas tecnologías de la información y comunicación.

b) La necesidad de satisfacer las necesidades materiales con mecanismos ajenos al mercado tradicional, dados los efectos de la crisis económica en el poder adquisitivo de la mayoría social, manifestado en la creciente desigualdad.

\subsection{El concepto de economía colaborativa}

Aunque no existe aún una definición comúnmente aceptada de economía colaborativa, se puede considerar que engloba un conjunto heterogéneo y rápidamente cambiante de modos de producción y consumo por el que los agentes comparten, de forma innovadora, activos, bienes o servicios infrautilizados, a cambio o no de un valor monetario, valiéndose para ello de plataformas sociales digitales y, en particular, de internet (CNMC, 2016).

En la economía colaborativa, el elemento común diferenciador es la intermediación de los servicios a partir de plataformas electrónicas ${ }^{6}$.

$\mathrm{Y}$ es que la extensión del uso de internet y aplicaciones móviles ha permitido singularizar la oferta clásica, haciendo mutar los servicios tradicionales por distintas vías, como son:

- La ampliación a nuevos segmentos de mercado.

- La desintermediación en la provisión de servicios.

- La incorporación de nuevos atributos que particularizan el producto o desdibujan la figura del proveedor y del consumidor (ciudadano proveedor o prosumidor).

Los nuevos modelos colaborativos operan ya de forma destacada en el transporte, el alojamiento, la financiación de proyectos, los servicios personales, la alimentación, la educación o la logística. En otros ámbitos su implantación es aún menor, como en el ámbito

\footnotetext{
${ }^{5}$ Así, Mandel (1975: 14-15), señala que la sociedad capitalista es la primera sociedad histórica donde la mayor parte de la producción está compuesta de mercancías, entendida como un producto que no ha sido creado para ser consumido directamente, sino que su finalidad consiste en ser cambiado en el mercado.

${ }^{6}$ Un análisis sobre el papel que juegan las plataformas en esta nueva forma de economía puede consultarse en Evans y Schamalensee (2016) o en Katz (2015).
} 
de la salud, la generación energética, los servicios empresariales o profesionales, la industria o las propias administraciones públicas, pero cuentan con potencial de crecimiento. Dada la heterogeneidad que presentan los distintos sectores colaborativos (transporte, alojamiento, compra/venta, finanzas, sistema monetario, entre otros), no es fácil acotar el concepto de economía colaborativa.

Sin embargo, siguiendo a Montero Pascual (2017), pueden distinguirse una serie de elementos identificativos de la misma, y otros que, sin ser definitorios, en muchos casos caracterizan los mercados colaborativos ${ }^{7}$.

\section{a) Elementos identificativos:}

- Nuevas tecnologías de la información y la comunicación. Tecnologías que permiten la interconexión de individuos previamente no relacionados en tiempo real a un mínimo coste.

- Mercados multilaterales. Es decir, mercados que relacionan, a través de una plataforma común, a dos grupos distintos de usuarios cuyo beneficio se deriva de la propia interacción de los mismos.

- Plataformas colaborativas. Erigidas como la máxima expresión de la economía digital, son el modo de organizar los mercados digitales, que permiten la interacción de dos grupos de usuarios (oferentes y demandantes).

- Sistemas de valoración. Los proveedores de servicios de la economía colaborativa deben someterse al escrutinio de los consumidores de dichos servicios, que generan en tiempo real información crucial para consumidores potenciales.

\section{b) Otras características de la economía colaborativa}

Como se ha mencionado con anterioridad, hay una serie de elementos que suelen estar presentes en los sectores colaborativos, pero cuya ausencia (y presencia de los elementos nucleares o sustanciales de la economía colaborativa) no puede inducirnos a pensar que no forman parte del paradigma colaborativo.

Esta distinción entre elementos centrales y secundarios no es baladí a la hora de regular estos sectores. Las bondades y riesgos que entraña la economía colaborativa suelen estar asociados con la presencia de determinadas características. Por ello, es imprescindible conocer en profundidad cada mercado colaborativo en particular para aplicarle una regulación acorde a su propia naturaleza.

En primer lugar, se encuentra el llamado "servicio entre iguales" (peer to peer o $P 2 P$, en inglés). Sería el caso en que las interacciones entre oferentes y demandantes en el mercado serían ejercidas por particulares no profesionales. Al poder situarse a ambos lados del mercado (oferta y demanda), los particulares son considerados como prosumidores (Rifkin, 2014). La evidencia empírica muestra cómo muchos de estos prosumidores acaban profesionalizando su actividad, por lo que limitar la economía colaborativa al ámbito de los particulares es un ejercicio de reduccionismo. No obstante, cabe advertir que se trata de una cuestión que suscita controversias. Lo que parece claro es que, a la hora de diseñar marcos

\footnotetext{
${ }^{7}$ Hay múltiples definiciones de economía colaborativa. Nosotros hemos optado por un concepto amplio, pero pueden consultarse otras definiciones más reduccionistas en Stoke et. al (2014) o Belk (2014), donde se consideran elementos identificativos el altruismo o la utilización de recursos ociosos.
} 
normativos, estos deben considerar la diferencia entre prestadores profesionales y prosumidores.

Un segundo elemento sobre el que reflexionar es la utilización de recursos ociosos. La tesis que subyace a esta característica es la creciente tendencia de sustituir el concepto de "consumo" por el de "uso" ". Si bien se trata de un elemento que incide significativamente en la eficiencia económica, no está presente en muchos de los actuales mercados colaborativos ${ }^{9}$, por lo que no lo consideramos elemento nuclear de la economía colaborativa.

En tercer lugar, estaría la contratación en tiempo real (on demand, en inglés). Al igual que sucedía con el caso anterior, se trata de una característica ajena a muchos mercados de la economía colaborativa. En contraste con la utilización de recursos ociosos, la contratación en tiempo real no encierra beneficios económicos tan significativos que ameriten un tratamiento diferencial desde la óptica del regulador.

Una última característica de la economía colaborativa es el altruismo, que junto con el $\mathrm{P} 2 \mathrm{P}$, es uno de los asuntos más controvertidos del paradigma colaborativo. Para no caer en el mencionado reduccionismo, que nos impediría comprender el fenómeno de la economía colaborativa en toda su magnitud, creemos más conveniente referirnos a "mercados colaborativos sin ánimo de lucro" (BlaBlaCar o Couchsurfing, por ejemplo) y "mercados colaborativos no altruistas", sin salirnos del paradigma colaborativo.

A partir de todo lo expuesto hasta ahora, podemos definir la economía colaborativa como un modelo de organización sectorial en el que, con la intermediación de una plataforma electrónica, un grupo de usuarios presta servicios a otro grupo de usuarios que generan información relevante para posteriores transacciones.

\subsection{Análisis económico de la economía colaborativa.}

La economía colaborativa, como nuevo modelo de organización económica, presenta una serie de características que lo diferencian de las estructuras tradicionales de mercado. Características, que son bien recibidas desde una perspectiva puramente económica pues, como veremos a continuación, eliminan o minimizan determinados fallos del mercado.

Lo primero que debemos destacar, y como se ha señalado en el epígrafe anterior, es que estamos ante mercados multilaterales ${ }^{10}$. Si el ejemplo clásico de este tipo de mercados eran los periódicos -donde los lectores compran noticias y los anunciantes espacio para su publicidad, todo ello facilitado por el propio medio de comunicación- las plataformas colaborativas son su expresión del siglo XXI.

Los mercados multilaterales son tanto más beneficiosos para sus usuarios cuanto mayor sea su número. Por ello, se dice que contienen externalidades de red. Es fácil advertir que cuanto mayor sea el número de prosumidores que hagan uso de una determinada

\footnotetext{
${ }^{8}$ Para una discusión más profunda sobre este cambio de paradigma se pueden consultar Bardhi y Eckhardt (2012); o Jefferson-Jones (2016).

${ }^{9}$ Muchas viviendas que hoy son VFT estaban antes destinadas al alquiler convencional. También se da el caso de inversores que adquieren un inmueble con la intención de ofertarlo en el mercado del alojamiento colaborativo. Del mismo modo, es habitual que los prestadores de transporte colaborativo adquieran un vehículo como inversión para la prestación del servicio.

${ }^{10}$ Las investigaciones sobre mercados multilaterales fundamentaron la concesión a Jean Tirole del Premio Nobel de economía en 2014. Véase su artículo junto con Rochet, titulado "Platform Competition in two sided markets", publicado en 2003.
} 
plataforma, mayor será el beneficio de acceder a ella en términos de alcance, variedad del producto o servicio, cantidad, precios, entre otros ${ }^{11}$.

Por otro lado, una de las características fundamentales del paradigma colaborativo es que permite una drástica disminución de los costes de transacción ${ }^{12}$, gracias a la labor de intermediación (o marco de contratación) que desarrollan las plataformas. Los costes de transacción son todos aquéllos que conlleva realizar una transacción en el mercado (búsqueda de información, costes de las negociaciones, de la celebración de contratos, entre otros). La presencia de dichos costes justificaban las grandes estructuras empresariales que caracterizaron la economía del siglo XX. En la actualidad, dicha dimensión pierde su sentido económico, entre otros motivos, por la caída de los costes de transacción que conlleva el paradigma colaborativo $^{13}$.

En tercer lugar, la posibilidad de que cualquier ciudadano que cuente con activos ociosos pueda convertirse en proveedor de los mismos, provoca directamente que los mercados afectados sean más contestables. Esto supone toda una garantía para contener los precios, pues cualquier subida injustificada de los mismos traerá consigo una entrada en el mercado de prosumidores dispuestos a ofrecer dicho bien o servicio a un menor precio. En el nuevo modelo, la competencia es por tanto más intensa y flexible, lo que redunda en el bienestar del consumidor y en la eficiencia económica.

En cuarto lugar, el nuevo modelo productivo colaborativo minimiza las asimetrías de la información que caracteriza las estructuras de mercado tradicionales y que justifican, junto con otros factores, las normas de protección al consumidor ${ }^{14}$. El sistema de valoración y reputación con que cuentan las plataformas colaborativas permite que los clientes potenciales cuenten con información más perfecta y generada en tiempo real del bien o servicio al que pretenden acceder. Si la información es más perfecta, la competencia es más efectiva, aumentando la eficiencia económica y el bienestar del consumidor ${ }^{15}$.

Finalmente, cabe destacar el capital liberado para otras inversiones por el fenómeno de los prosumidores. Bajo el paradigma colaborativo, hay sectores (como el del alojamiento) que deberán redimensionarse, producto de la entrada de nuevos prestadores de bienes o servicios a partir de activos ociosos. Esto implica que parte del capital hoy invertido en dichos bienes o servicios puede destinarse o bien a otros sectores económicos, o bien al mismo sector para profundizar en la innovación y adaptarse a la nueva estructura de mercado; redundando en ambos casos en el crecimiento económico y en la creación de empleo.

\section{La economía colaborativa: un nuevo reto para las autoridades de competencia}

La libre competencia, o la competencia efectiva, es un elemento clave en la economía de mercado que beneficia a todos los consumidores y fomenta la innovación, la eficiencia

\footnotetext{
${ }^{11}$ Sin embargo, todavía no contamos con una definición clara y consensuada de las características que debe reunir una plataforma para considerar que opera en un mercado multilateral (Codagnone y Bertin, 2016).

${ }^{12}$ Concepto acuñado por el también Nobel, Ronald Coase en 1937, en su artículo "The nature of the Firm".

${ }^{13}$ Otros motivos son la falta de flexibilidad que caracterizaba a estas estructuras, lo que suponía todo un hándicap a la hora de competir en los mercados actuales, caracterizados por el dinamismo; o la drástica reducción de aranceles y costes de transporte, que permite que empresas de cualquier rincón del mundo puedan especializarse en productos intermedios y distribuirlos globalmente.

${ }_{15}^{14}$ Éste es el motivo de que a los hoteles se les categorice con estrellas.

${ }^{15}$ Esto no quiere decir que no se necesiten normas para la protección de los consumidores. Más bien se trata de adaptar las mismas a las nuevas características de los mercados colaborativos cuando sea necesario (Koopman et al, 2015).
} 
productiva y la dinámica empresarial. La evidencia empírica demuestra que los países donde existe competencia efectiva tienen, relativamente, bajos índices de desempleo, inflación y pobreza. También está acreditado que estos países gozan de mayor calidad de vida y bienestar para sus habitantes.

A grandes rasgos, las autoridades de competencia son organismos públicos que tienen como fines generales promover y preservar el funcionamiento competitivo de los mercados, así como contribuir a la mejora y la eficiencia de su regulación económica, garantizando la existencia de una competencia efectiva en los mismos y protegiendo los intereses generales.

Como hemos señalado con anterioridad, la economía colaborativa se ha convertido en los últimos años en un fenómeno innovador de alcance global y transversal, que está generando importantes cambios estructurales en el funcionamiento de los mercados. Esto explica que se haya convertido en objeto de estudio por parte de las autoridades de competencia. En opinión de la CNMC (2017), la economía colaborativa requiere y requerirá durante los próximos años de un análisis en profundidad desde el punto de vista de la competencia y la regulación económica eficiente.

En primer lugar, el aumento del número y tipo de oferentes, junto con la mayor variedad de los productos y servicios que acompaña a estos nuevos modelos, representa una oportunidad desde el punto de vista de la competencia y la mejora de la regulación.

Asimismo, habría otras ventajas económicas también relacionadas con la eficiencia: una mayor información contrastable sobre los productos y servicios, reducción de precios con niveles similares de calidad, mercados más profundos y completos, y una asignación más eficiente de recursos infrautilizados, especialmente en bienes más intensivos en capital.

En tercer lugar, muchas de estas plataformas podrían estar contribuyendo, de forma menos distorsionadora de la competencia, a mitigar fallos de mercado y a la consecución socioeconómica de diversos objetivos de imperioso interés general como, por ejemplo, el orden público, la salud pública, la seguridad pública y la protección del medioambiente.

En cuarto lugar, se constata una mejora de la eficiencia y productividad de los mercados, lo cual repercute positivamente sobre la competitividad de la economía y el crecimiento económico.

Finalmente, la aparición de esta nueva economía, que podría estar configurando un Cuarto Sector, solapado y complementario a los tres tradicionales, plantea numerosos retos para los agentes económicos tradicionales (incumbentes), que deben adaptarse, y para el sector público, desde el punto de vista de la regulación. Entre otros motivos, porque los modelos de regulación existentes, se diseñaron conforme a la realidad tecnológica, económica y social de los mercados de aquel momento. Un marco en el que no había aún aparecido los actuales modelos de economía colaborativa y de prestación de servicios por internet.

Así pues, la situación actual en estos mercados plantea una oportunidad, para la valoración y revisión de las normas que los regulan, de acuerdo con los principios de regulación económica eficiente y de fomento de la competencia en los mercados. Es decir, deberían mantenerse únicamente aquellas regulaciones justificadas por la existencia de fallos de mercado; si la regulación horizontal o sectorial actuase como una barrera innecesaria o desproporcionada, dificultando la entrada al mercado o al ejercicio de la economía colaborativa y las nuevas plataformas de prestación de servicios, dicha regulación no estaría alineada con los principios de regulación económica eficiente y convendría modificarla y adaptarla. 
Sin una normativa fundada en los principios de la regulación económica eficiente, lo cual puede implicar en determinados casos, la ausencia de normativa, podría peligrar el aprovechamiento de estas innovaciones generadoras de oportunidades y de competencia, con la consiguiente pérdida en términos de bienestar de la sociedad y perjuicio para el interés general $^{16}$.

Asimismo, las autoridades de competencia deben ser conscientes de los riesgos que entraña esta nueva economía. En este sentido, existe la posibilidad de que una plataforma colaborativa dominante aproveche su poder de mercado a otros mercados explotando el valor o la ventaja competitiva derivada de su gran base de datos ${ }^{17}$ (Lougher y Kalmanowicz, 2016).

En suma, la economía colaborativa se configura como un fenómeno económico, social y tecnológico imparable e inevitable a nivel mundial, que los ciudadanos, los operadores económicos y las administraciones públicas, deben entender e incorporar en sus respectivas actuaciones para aprovechar plenamente los beneficios que de él se derivan. Este fenómeno es pues una oportunidad, una nueva fuente de innovación, productividad, dinamismo y crecimiento económico y, por ello, la regulación ineficiente no debe impedir su desarrollo y aprovechamiento por parte de todos.

\section{Regulación y competencia en el mercado de las viviendas turísticas.}

El presente apartado trata de delimitar las características de este sector emergente, contrastándolas con el modelo tradicional, para identificar tanto los beneficios como los costes del cambio de paradigma en el mercado de las viviendas turísticas. El epígrafe recoge, asimismo, las orientaciones que emanan de la UE para la mejora de la regulación de la economía colaborativa en general y del mercado de las VFT en particular.

La entrada del sector de las VFT en el mercado del alojamiento turístico ha generado una problemática en el ámbito de la regulación, la cual consiste en:

a) Aplicar de forma homogénea el marco regulador vigente a los nuevos entrantes, especialmente en el pago de impuestos.

b) Adaptar el marco regulador para garantizar el correcto encaje de estas nuevas actividades.

c) Plantear la cuestión de cuál es el papel que juegan las plataformas y en qué medida estas son responsables del servicio que intermedian.

d) Determinar el papel de cada una de las administraciones competentes.

Esta problemática ha dado lugar a cambios en la regulación, por parte de las administraciones públicas competentes. En ocasiones, flexibilizando y eliminando restricciones existentes en el marco regulador vigente para acoger este tipo de alojamientos en el mercado. En otros casos, restringiendo la oferta de estas viviendas de uso turístico, como está siendo, por el momento, el caso más habitual entre las administraciones autonómicas en el Estado español, como veremos a continuación.

\footnotetext{
${ }^{16}$ En este punto cabe advertir que hay autores, como Cohen y Sundararahan, (2015), que confían en que la autorregulación es la mejor de las alternativas regulatorias en el ámbito de la economía colaborativa.

${ }^{17}$ Por ejemplo, una plataforma de viaje compartido, por ejemplo, tiene un conocimiento intrínseco del paradero y los patrones de gasto habituales del consumidor.
} 
En concreto, la modificación de la Ley de Arrendamientos Urbanos (en adelante, LAU), en 2013, implicó que la regulación de las viviendas de uso turístico fuera asumida por las Comunidades Autónomas ${ }^{18}$.

Desde entonces, han surgido numerosas normativas autonómicas y locales ${ }^{19}$, que imponen restricciones de acceso y ejercicio, injustificadas y desproporcionadas, al mercado de alojamiento turístico, con efectos negativos sobre la competencia y el bienestar. Las barreras a la competencia efectiva generadas por la normativa se oponen a la innovación y reducen el dinamismo del mercado. Sin embargo, las normas deben considerar, además de los beneficios económicos del alojamiento colaborativo, las posibles externalidades, que en este ámbito consisten, básicamente, en los cambios que se producen en los barrios producto del desembarco de turistas y de la reducción de oferta de vivienda para residentes (Edelman y Gerardin (2016).

\subsection{El nuevo modelo de alojamiento colaborativo}

A partir de distintas normativas autonómicas ${ }^{20}$, la actividad de alojamiento temporal puede definirse como la prestación de hospedaje o residencia, a cambio de un precio, en la que se añade la asistencia al arrendatario y que puede incluir la prestación de otros servicios complementarios. Por tanto, se trata de una actividad que se diferencia a la del alquiler tradicional, primero, en su temporalidad. Y segundo, y más importante, en la asistencia que recibe el cliente desde el momento de la ocupación de la vivienda, sin desvirtuar su naturaleza el hecho de que se presten todos o solamente algunos de los servicios (Franch Fluxá y Ribas Conrado, 2013).

El mercado colaborativo del alojamiento turístico está cambiando el sector a una velocidad sin precedentes. Los cambios culturales están provocando que los turistas valoren cada vez más las experiencias genuinas. Se trata de huir del modelo que ha predominado durante las últimas décadas, caracterizado por los viajes programados y los paquetes turísticos (las llamadas "vacaciones en lata”).

$\mathrm{Si}$ al hecho de poder conocer la idiosincrasia del lugar visitado y compartir con los residentes del destino turístico, se añade una oferta flexible, competitiva, y con una gran variedad, estamos claramente ante un nuevo modelo productivo en el sector del alojamiento turístico $^{21}$. Obviamente, nada de esto estaría sucediendo sin los avances tecnológicos que

\footnotetext{
${ }^{18}$ El pasado 23 de mayo de 2017 se celebró en Madrid la Conferencia Sectorial de Turismo, con presencia de todas las Comunidades Autónomas, en la que se abordaron aspectos como la regulación de la vivienda vacacional o la nueva estrategia de promoción de Tur España. En la citada Conferencia, los representantes de varias CC.AA. expresaron su voluntad de trabajar por construir regulaciones más homogéneas, a partir del intercambio de experiencias y orientaciones por parte de las diferentes administraciones autonómicas con competencias en esta materia, para abordar el crecimiento del uso turístico de viviendas.

${ }^{19}$ La Federación Española de Municipios y Provincias (FEMP) el pasado 2 de febrero de 2017 trasladó a la Secretaria de Estado de Turismo la demanda de las Administraciones Locales de que el Gobierno se implique en la regulación del alquiler de viviendas de uso turístico. El objetivo es que haya una norma a nivel nacional que regule la actividad económica de este sector y que, al mismo tiempo, contribuya a garantizar la sostenibilidad y competitividad de la oferta turística en España. Los ayuntamientos quieren que se elabore un estudio sobre la situación actual de este tipo de alquiler.

${ }^{20}$ Para una discusión más profunda sobre la delimitación conceptual de la actividad de alojamiento temporal en la normativa autonómica puede consultarse Guillén Navarro e Íñiguez Barrozpe (2016).

${ }^{21}$ Este cambio de paradigma tiene repercusiones desde el punto de vista de la regulación. El interés general del turismo va desplazándose paulatinamente desde la calidad hacia la cantidad, desde lo exclusivo hacia lo popular.
} 
permiten la interconexión de individuos previamente no relacionados a un coste casi cero (disrupción tecnológica). La gran cantidad de viviendas vacías (sobre todo en el Estado español) y la necesidad de buscar complementos de renta ante la caída de salarios reales que sucedió a la crisis de 2009, también han coadyuvado al desarrollo del modelo descrito.

Según la CNMC (2016), el alojamiento, junto con el transporte, es uno de los sectores de la economía colaborativa que mayor desarrollo está experimentando ${ }^{22}$. Por ello, su impacto sobre la competencia con los operadores establecidos o incumbentes está siendo significativo, dando lugar a una situación de concurrencia entre el modelo tradicional y el alojamiento colaborativo que merece un análisis.

En primer lugar, hay que ser conscientes de las consecuencias económicas de la disrupción tecnológica. En el mercado del alojamiento, al igual que sucede en otros mercados, ya no son necesarias elevadas sumas de capital fijo para participar en el mismo. La caída en picado de los costes de transacción que acarrea la disrupción tecnológica permite que muchos prosumidores pasen a formar parte de la oferta. Donde hoy predominan las grandes cadenas hoteleras, es probable que veamos como paulatinamente estas estructuras vayan dando paso a una oferta más flexible y menos jerárquica.

En segundo lugar, la entrada en escena de las VFT en el mercado del alojamiento, provoca los mismos efectos que los que aparecen en los manuales de teoría económica: menores precios y mayor variedad de productos (o servicios, en este caso). La mayor variedad en la oferta es especialmente interesante en el mercado del alojamiento turístico, ya que se trata de un mercado que capta renta extranjera y con una demanda potencial muy alta. La mayor variedad en la oferta se traduce en menores precios de todas las categorías, mayores alternativas en términos geográficos y mayor variedad en cuanto a decoración/distribución y demás características propias de un alojamiento.

Tercero, las VFT constituyen un servicio cualitativamente distinto al que se oferta en el alojamiento tradicional (excluido el apartamento vacacional). Además del alojamiento, pernoctar en una VFT le permite al turista conocer a un residente local (cuando no convivir con él), lo que abre un abanico de posibilidades informativas, culturales y de servicios conexos. A este tratamiento más personalizado que recibe el turista, hay que añadir la posibilidad del uso de servicios anexos al alojamiento como la cocina, lo que provoca que el comercio de proximidad se beneficie. Por otro lado, las VFT no cuentan con el servicio de limpieza durante la estancia que sí está presente en el alojamiento tradicional. En definitiva, los servicios son cualitativamente distintos.

En cuarto lugar, el nuevo modelo del turismo colaborativo minimiza las asimetrías de la información, presente en el alojamiento tradicional ${ }^{23}$. El sistema de valoración y reputación con que cuentan las plataformas colaborativas del alojamiento turístico permiten que los clientes potenciales cuenten con información más perfecta y generada en tiempo real del servicio que pretenden contratar. Si la información es más perfecta, la competencia es más efectiva, aumentando la eficiencia económica.

\footnotetext{
Sin duda, la consolidación de los vuelos low cost han contribuido de manera decisiva a este cambio de tendencia en el sector turístico (Lora-Tamayo Vallvé, 2016).

${ }^{22}$ Cabe advertir que hay autores que consideran que no todo el alquiler a corto plazo realizado por individuos a través de plataformas digitales pertenece al ámbito de la economía colaborativa. Una discusión más profunda sobre el particular puede consultarse en Oskam y Boswijk (2016).

${ }^{23}$ Ver nota 11.
} 
En definitiva, la estructura del mercado del alojamiento, que ha resultado de la irrupción del fenómeno de las VFT bajo el paraguas de las plataformas colaborativas, puede considerarse positiva desde el punto de vista económico, pues se asemeja más a los postulados de la competencia perfecta que el modelo anterior: mayor número de oferentes, mejores precios, mayor variedad en el servicio, mayor facilidad de entrada y salida del mercado e información más perfecta se traducen en que la economía funciona con mayores niveles de eficiencia, lo que redunda en el bienestar del consumidor.

\subsection{Orientaciones europeas para la mejora de la regulación económica en el mercado de las viviendas con fines turísticos}

A nivel comunitario, las relaciones entre las tres partes -proveedor, plataforma y consumidor- que protagonizan el intercambio de servicios de alojamiento están sujetas a distintas regulaciones que, si bien no fueron diseñadas para el fenómeno colaborativo (especialmente por la dimensión que está adquiriendo), siguen vigentes en la actualidad.

En el caso del proveedor, su regulación se deriva de la Directiva de Servicios (2006), que establece que las restricciones de acceso al mercado deben ser no discriminatorias, ser proporcionadas y estar justificadas. Por su parte, la labor de intermediación de las plataformas colaborativas se regulan a partir de la Directiva de Comercio Electrónico (2000), donde se recoge que los servicios de la sociedad de la información deben estar sujetos a mínimos requisitos de regulación. La excepción de esta tríada la constituye el consumidor, al que no se le aplican las normas de protección al consumidor, dado que estas afectan a las relaciones entre comerciantes y consumidores; y ni las plataformas colaborativas ni los proveedores de servicio de alojamiento lo son (Smorto 2016).

La situación descrita, junto con el diferencial existente entre emprendimientos europeos y norteamericanos en el ámbito de la economía colaborativa, explican los recientes pasos de la UE para comprender el paradigma colaborativo (Demary, 2015). La dimensión y relevancia que la economía colaborativa viene adquiriendo en los últimos años no han pasado desapercibidos para las autoridades europeas, tradicionalmente preocupadas y ocupadas por la innovación. Prueba de ello es la publicación de distintos documentos y comunicaciones de interés sobre la materia, entre las que destaca la Agenda Europea para la Economía Colaborativa $(2016)^{24}$.

Asimismo, el Parlamento Europeo ha identificado una serie de retos de la economía colaborativa que deben ser abordados para aprovechar el potencial de este nuevo paradigma (Goudin, 2016):

a) Definir correctamente las plataformas digitales. Es decir, establecer criterios claros para determinar a qué categoría legal pertenecen las plataformas.

b) Mejorar el marco regulador de las plataformas colaborativas. La gran cantidad de datos recopilados por las mismas pueden ser utilizados, por un lado, con fines fiscales, para minimizar la economía sumergida y los costes de la recaudación vía impuestos; y, por otro, para realizar estudios que permitan comprender el fenómeno colaborativo y sirvan así de insumos para la labor continua que supone la mejora de la regulación económica.

\footnotetext{
${ }^{24}$ Otras iniciativas relevantes sobre el particular son el Workshop sobre economía colaborativa celebrado en 2016 al amparo del Parlamento Europeo; o los analytical papers dedicados a las restricciones para operar en el mercado VFT en distintas ciudades europeas (en concreto, se han estudiado los casos de Barcelona, Berlín, Ámsterdam, Milán, París, Roma, Londres, Estocolmo, Budapest y Bruselas.
} 
c) Mitigar la "exclusión social" que puede producirse por malas valoraciones de usuarios.

d) Abordar el potencial poder de mercado de las plataformas colaborativas, para evitar posiciones de dominio.

e) Aplicar la regulación del mercado laboral a la economía colaborativa. En concreto, se propone incluir a los proveedores de servicios de economía colaborativa en el ámbito de las normas generales para auto empleados.

Por su parte, la Comisión de Turismo y Transporte reconoce el efecto positivo de la economía colaborativa en el sector del turismo, ya que refuerza las posibilidades de ingresos individuales y de las economías locales, al tiempo que proporciona instrumentos para responder mejor a las fluctuaciones de la demanda. Asimismo, sostiene que el alojamiento colaborativo refleja las diferentes preferencias de los viajeros, en especial los que tienen unos ingresos más bajos. Así, la Comisión de Turismo y Transporte defiende la necesidad de favorecer una coexistencia beneficiosa entre los servicios turísticos tradicionales y la economía colaborativa (Comisión de Mercado Interior y Protección al Consumidor, 2017).

Por otro lado, de los cinco aspectos clave de la economía colaborativa que destaca la Comisión Europea (2016), los requisitos de acceso al mercado son los que están revelándose como más preocupantes en el mercado del alojamiento colaborativo. Esto se debe a que dichos requisitos están diseñados para el negocio tradicional del alojamiento, por lo que es más que probable que muchos de ellos no sean apropiados para el emergente modelo del turismo colaborativo. En otras palabras, la regulación existente puede no ser eficaz, ser innecesaria, o ser desproporcionada (principios de la mejora de la regulación económica) para los operadores emergentes del mercado del alojamiento colaborativo 25 .

En definitiva, las instituciones europeas reconocen el beneficio potencial que encierra el paradigma colaborativo. Sin embargo, para que este se materialice, hay que estar atentos a las dinámicas de dichos mercados para ofrecer respuestas reguladoras satisfactorias. Por ello, la Comisión Europea está impulsando desde febrero de 2017 una serie de workshops sobre cuestiones en materia de regulación del alojamiento colaborativo. El objetivo no es otro que promover las buenas prácticas por el territorio europeo y combatir la fragmentación del mercado único.

\section{El sector de las viviendas turísticas en España: el análisis de las autoridades de competencia}

Como se ha señalado, en los últimos años, la CNMC y las autoridades autonómicas de competencia han centrado su atención sobre algunas normativas autonómicas de viviendas turísticas, que contienen requisitos y condiciones específicas que limitan la entrada y la capacidad de competir de esta tipología de operador. Estas restricciones a la competencia privilegian a los operadores económicos ya instalados y reducen el bienestar general.

En este sentido, tanto la CNMC como las autoridades autonómicas de competencia han elaborado informes de la regulación autonómica sobre este tipo de alojamientos turísticos, llegándose en algunos casos a hacer uso, por parte de la CNMC, del mecanismo de legitimación activa contemplado en la Ley 15/2007, de 3 de julio, de Defensa de la Competencia, que le permite la impugnación de normas. Ello ha sucedido hasta el momento

\footnotetext{
${ }^{25}$ Prueba de ello son las iniciativas que se están emprendiendo en el estado español, a nivel autonómico, para regular apropiadamente el fenómeno de las VFT.
} 
actual en cuatro ocasiones, sobre las normativas de las viviendas vacacionales que han tramitado las Comunidades Autónomas de Madrid, Canarias, Castilla y León y Galicia.

En este apartado se analizan las iniciativas de las distintas Comunidades Autónomas del Estado español para regular el mercado de las VFT, y las actuaciones realizadas por las distintas autoridades de competencia al respecto. En una primera fase se estudia la regulación específica de Andalucía, que tienen en su haber el no haber sido recurrida en los tribunales ni informada negativamente. Posteriormente, se presenta un estudio comparativo de las regulaciones de varias comunidades (aquéllas en las que el turismo tiene un mayor peso económico, más Aragón y Castilla y León), para identificar las restricciones a la competencia que han motivado sus respectivos recursos e informes negativos.

\subsection{La regulación de las viviendas con fines turísticos en Andalucía}

\subsubsection{Breve panorámica del mercado de alojamiento turístico en Andalucía}

Antes de profundizar en el análisis del marco regulador, conviene hacer una digresión para considerar la importancia que tiene el sector turístico en Andalucía, territorio que no se destaca por una alta actividad industrial y cuyas exportaciones adolecen en muchos casos de valor añadido. Por ello, el turismo se erige como un sector clave para el crecimiento económico y el empleo, representando el $12.5 \%$ del PIB y el 11,9\% del empleo (Exceltur, 2017).

La buena salud de la que goza el sector turístico andaluz, y sus perspectivas de crecimiento, lo demuestra la creciente tendencia a elegir Andalucía como destino turístico. La Ilustración 1 recoge la evolución del número de turistas que visitaron Andalucía en el período 2008-2016. A pesar de ser unos años marcados por la crisis financiera y sus efectos, Andalucía ha pasado de recibir poco más de 25 millones de turistas en 2008 a los más de 28 millones de 2016, lo que supone un incremento del 12,05\% en el período considerado.

Ilustración 1. Evolución del número de turistas en Andalucía

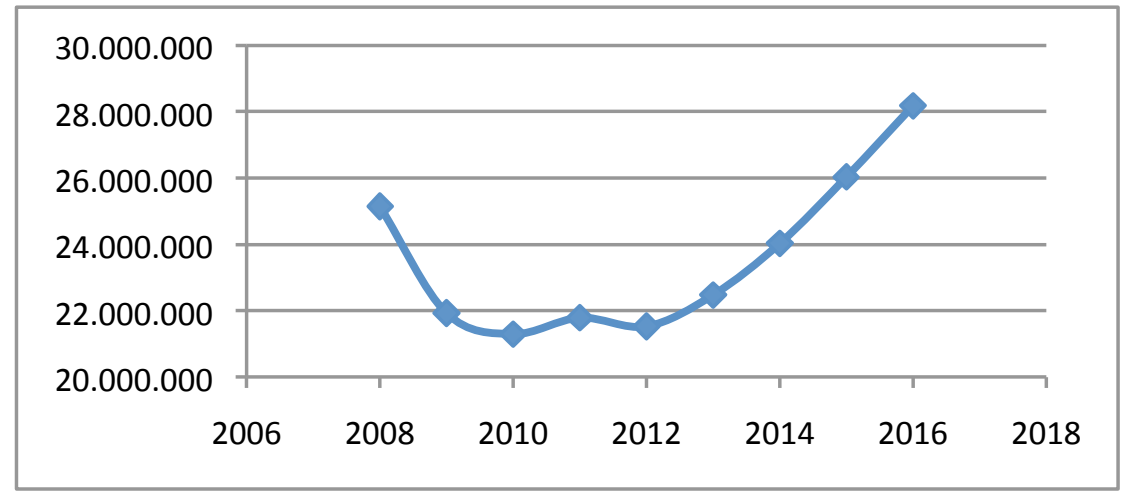

Fuente: Elaboración propia a partir de datos del IECA.

Además de que cada vez más turistas eligen Andalucía como destino, el gasto de estos también está aumentando. Como puede apreciarse en la Ilustración 2, este ha pasado de los $58,5 €$ de gasto medio diario de 2008 a los casi $65 €$ en 2016, lo que supone un incremento de más del $10 \%$ en el período considerado. Además, si solo tenemos en cuenta los cuatro últimos años, el gasto medio diario ha pasado de 58,9 $€$ a los actuales $65 €$, lo que, descontando la inflación acumulada (-0.513\%), nos da un incremento en términos reales de más del $15 \%$. 
Ilustración 2. Gasto medio diario de los turistas en Andalucía 2008-2016.

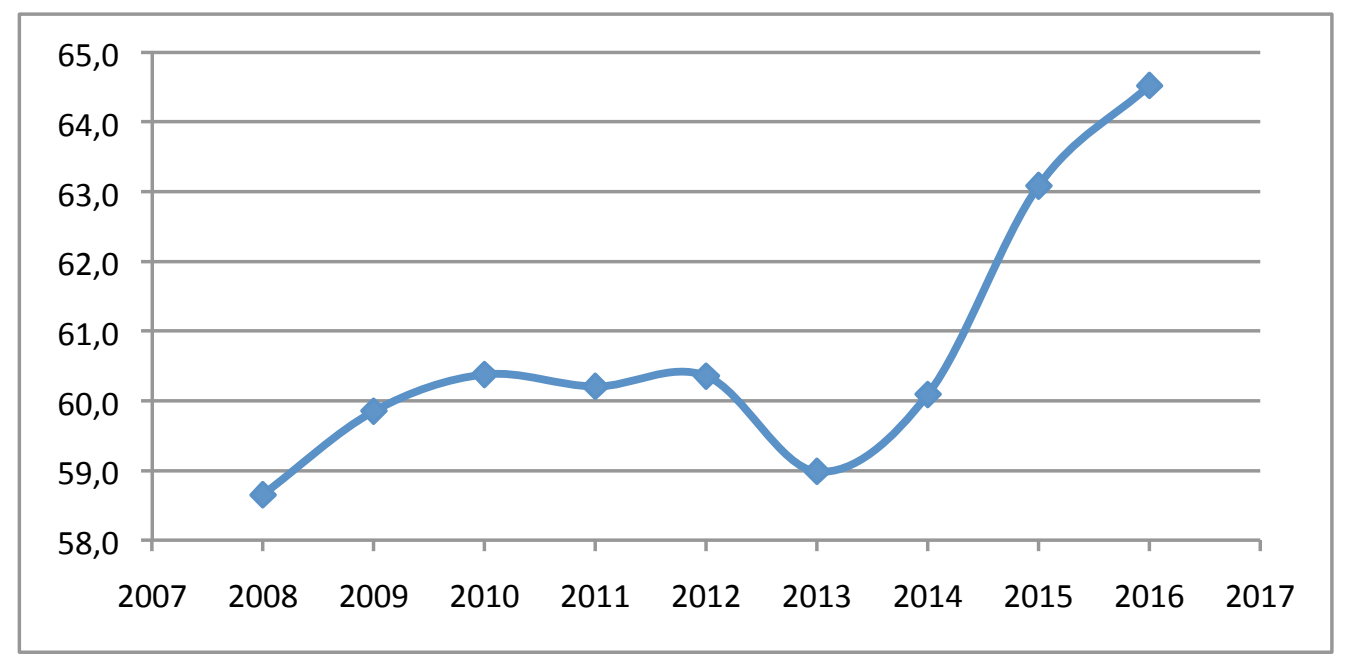

Fuente: Elaboración propia a partir de datos del IECA. Encuesta de coyuntura Turística.

Una vez comprobado el crecimiento sostenido que presenta el turismo en Andalucía, se puede pasar a analizar el mercado del alojamiento turístico, considerando todas las opciones disponibles para el visitante. En este sentido, a la oferta tradicional (apartamentos, hoteles, pensiones, entre otros) hay que añadir la novedad del alojamiento colaborativo.

La Tabla 1 muestra la distribución de los turistas que visitan Andalucía en función del alojamiento elegido. De los más de 21 millones de turistas que se hospedaron en Andalucía en 2016, más de 17 millones se decantaron por el hotel, lo que representa más del $80 \%$ del total; en segundo lugar estarían los apartamentos (9,5\%), seguidos de los campings $(4.6 \%)$ y de los alojamientos propios del turismo rural $(1,23 \%)$. Se observa por tanto un fuerte desequilibrio a favor de los hoteles.

Asimismo, es interesante reflexionar sobre la evolución que registra cada una de las categorías de alojamiento en el período 2009-2016. En suma, el número de viajeros que visitan Andalucía ha crecido un 30\%. Atendiendo a las distintas categorías, se observa que los apartamentos son los que han experimentado un mayor aumento de demanda, de más del $137 \%$. A continuación se encuentran el turismo rural (casi 60\%) seguido por los hoteles $(25,52 \%) \mathrm{y}$, finalmente, por los campings $(8,9 \%)$.

Por tanto, puede afirmarse que los turistas se decantan cada vez más por los apartamentos como alojamiento para sus visitas a Andalucía. En cualquier caso, hay que ser prudentes con dicha aseveración ya que, a pesar de la tendencia descrita, el número de viajeros hospedados en hotel sigue siendo muy superior (más de 17 millones frente a dos millones) al que se aloja en apartamentos.

Tabla 1. Distribución de los turistas en Andalucía en función del alojamiento

\begin{tabular}{|l|r|r|r|r|r|r|r|r|r|}
\hline \multicolumn{7}{|c|}{ VIAJEROS ALOJADOS EN ALOJAMIENTOS REGLADOS EN ANDALUCÍA } \\
\hline & 2009 & 2010 & 2011 & 2012 & 2013 & 2014 & 2015 & 2016 & $\begin{array}{l}\text { V\% } \\
16\end{array}$ \\
\hline Hoteles & 14.205 .603 & 14.396 .885 & 14.838 .711 & 14.451 .587 & 14.944 .271 & 15.589 .124 & 16.677 .900 & 17.831 .269 & $25,52 \%$ \\
\hline Campings & 893.279 & 830.973 & 786.902 & 761.213 & 778.909 & 827.840 & 909.204 & 972.770 & $8,90 \%$ \\
\hline Apartamentos & 867.631 & 1.014 .410 & 1.086 .160 & 1.179 .570 & 1.353 .751 & 1.609 .261 & 1.820 .108 & 2.061 .722 & $137,63 \%$ \\
\hline Turismo rural & 166.164 & 146.225 & 146.969 & 165.431 & 185.155 & 201.538 & 224.459 & 265.773 & $59,95 \%$ \\
\hline Total & 16.132 .677 & 16.388 .493 & 16.858 .742 & 16.557 .801 & 17.262 .086 & 18.227 .763 & 19.631 .671 & 21.131 .534 & $30,99 \%$ \\
\hline
\end{tabular}

Fuente: Elaboración propia a partir de los datos del INE. 
Atendiendo a las pernoctaciones, en lugar de al número de turistas (Tabla 2), puede apreciarse cómo han aumentado un porcentaje similar a los viajeros (más del 30\%) en el período considerado. Sin embargo, en esta ocasión el incremento de los apartamentos no es tan pronunciado como en el caso del número de viajeros. Esto lleva a pensar que los turistas se decantan cada vez más por el apartamento, pero estos se hospedan menos noches que los que tradicionalmente elegían el apartamento como alojamiento en sus estancias. El fenómeno VFT parece estar desplazando plazas que otrora se ocupaban por largos períodos (15 días/ un mes) hacia la oferta a corto plazo.

Tabla 2. Pernoctaciones registradas en alojamientos reglados en Andalucía.

\begin{tabular}{|l|r|r|r|r|r|r|r|r|r|}
\hline \multicolumn{8}{|c|}{ PERNOCTACIONES REGISTRADAS EN ALOJAMIENTOS REGLADOS EN ANDLUCÍA } \\
\hline & 2009 & 2010 & 2011 & 2012 & 2013 & 2014 & 2015 & 2016 & $\begin{array}{l}\text { V\% 09- } \\
16\end{array}$ \\
\hline Hoteles & 40.681 .215 & 40.915 .968 & 42.230 .707 & 41.181 .764 & 43.021 .364 & 45.026 .227 & 47.957 .515 & 51.536 .425 & $26,68 \%$ \\
\hline Campings & 3.771 .685 & 3.602 .802 & 3.390 .990 & 6.293 .605 & 6.791 .433 & 7.784 .474 & 8.728 .491 & 4.026 .679 & $6,76 \%$ \\
\hline Apartamentos & 51.947 .18 & 5.650 .729 & 5.811 .047 & 3.418 .334 & 3.279 .256 & 3.483 .134 & 3.805 .010 & 9.423 .229 & $81,40 \%$ \\
\hline Turismo rural & 551.240 & 496.399 & 506.272 & 602.512 & 643.949 & 717.351 & 765.137 & 921.109 & $67,10 \%$ \\
\hline Total & 50.198 .858 & 50.665 .898 & 51.939 .016 & 51.496 .215 & 53.736 .002 & 57.011 .186 & 61.256 .153 & 65.907 .442 & $31,29 \%$ \\
\hline
\end{tabular}

Fuente: Elaboración propia a partir de datos del INE.

Esta sospecha se confirma con la Tabla 3, que recoge la estancia media de los turistas en Andalucía por categorías de alojamiento. En el período considerado (2009-2016), la estancia media del turista hospedado en apartamentos se ha reducido un $23,7 \%$, pasando de los 6 días de media en 2009 a los actuales 4,57 días. Esto indica que, para estancias cortas, donde el hotel ha sido tradicionalmente la categoría que ha satisfecho esta demanda, los turistas se decantan cada vez más por la fórmula del apartamento. A pesar de que el hotel sigue siendo el hospedaje predominante para estancias cortas (la estancia media es de menos de tres días), este registra una tendencia creciente; es decir, la estancia en hoteles aumenta poco más de un $1 \%$ en el período considerado. Asimismo, es destacable que la estancia media del turista se reduce en dicho período un $5 \%$.

Tabla 3. Estancia media en alojamientos reglados en Andalucía.

\begin{tabular}{|l|r|r|r|r|r|r|r|r|r|}
\hline \multicolumn{6}{|c|}{ ESTANCIA MEDIA EN ALOJAMIENTOS REGLADOS EN ANDALUCÍA } \\
\hline & 2009 & 2010 & 2011 & 2012 & 2013 & 2014 & 2015 & 2016 & \multicolumn{2}{l|}{$\begin{array}{l}\text { V\% 2009- } \\
\end{array}$} & 2,86 & 2,84 & 2,85 & 3,11 & 3,11 & 2,89 & 2,88 & 2,89 & $1,05 \%$ \\
\hline Hoteles & 4,22 & 4,34 & 4,31 & 5,34 & 5,02 & 4,84 & 4,8 & 4,14 & $-1,90 \%$ \\
\hline Campings & 5,99 & 5,57 & 5,35 & 4,49 & 4,21 & 4,21 & 4,18 & 4,57 & $-23,71 \%$ \\
\hline Apartamentos & 3,32 & 3,39 & 3,44 & 3,64 & 3,48 & 3,56 & 3,41 & 3,47 & $4,52 \%$ \\
\hline Turismo rural & 3,11 & 3,09 & 3,08 & 3,11 & 3,11 & 3,13 & 3,12 & 3,12 & $-5,01 \%$ \\
\hline Total & &
\end{tabular}

Fuente: elaboración propia a partir de los datos del INE

Esta caracterización general del alojamiento turístico en Andalucía se completa con la Tabla 4, donde se recoge el número de plazas ofertadas en función del tipo de alojamiento. Para analizar con mayor nivel de detalle la oferta de alojamiento, se han dividido los hoteles en 3 categorías: los de 4 y 5 estrellas, por un lado; los de tres estrellas, por otro; y los de una y dos estrellas, por otro lado. Asimismo, se ha incluido, además de la variación porcentual del período considerado (2009- 2016), la variación porcentual del último año, ya que es cuando 
empiezan a registrarse las VFT al calor del Decreto 28/2016, de 2 de febrero, de las viviendas con fines turísticos.

Observando la Tabla 4, puede apreciarse cómo, en el período 2011-2016, las tres categorías en que hemos dividido la oferta hotelera registran una tendencia decreciente en el número de plazas ofertadas, siendo los hoteles de tres estrellas los más damnificados por el cambio de modelo que está provocando la irrupción de las VFT (-13,18\% en el último año). En contraste, el número de plazas ofertadas por hostales (que incluyen pensiones y albergues), ha aumentado un $11,31 \% \%$ en el período considerado (13,17\% en el último año), mientras que las de los apartamentos han aumentado un 4,76\% (15,85\% en el último año). Por su parte, las plazas de VFT registradas a finales de 2016 ascendían 167.923, por lo que se sitúan muy cerca de los hoteles de 4 y 5 estrellas, el tipo de alojamiento predominante en Andalucía medido por el número de plazas ofertadas. Viendo el crecimiento que están experimentando las VFT, es de esperar que en los próximos meses supere a los hoteles en lo que a número de plazas se refiere. De hecho, según la Consejería de Turismo, el número de plazas ofertadas por VFT ya supera a las hoteleras en la Costa del Sol ${ }^{26}$.

\footnotetext{
26 A 27 de octubre de 2017, los datos cifran en 80.872 las plazas de viviendas con fines turísticos inscritas en el Registro de Turismo en la provincia de Málaga, frente a las 79.577 que suman los hoteles de entre una y cinco estrellas (Diariosur, 6 de septiembre de 2017).
} 
Tabla 4. Oferta de alojamiento turístico en Andalucía. Número de plazas.

\begin{tabular}{|lrrrrr|}
\hline OFERTA DE ESTABLECIMIENTOS DE ALOJAMIENTO TURÍSTICO EN ANDALUCÍA. N $\mathbf{N}^{\mathbf{0}}$ & PLAZAS \\
\hline & 2011 & 2015 & \%Var $2011-2016$ & 2016 & $\%$ Var 2015-2016 \\
Hoteles 4 y 5* & 163.541 & 169.482 & $3,09 \%$ & 168.601 & $-0,52 \%$ \\
Hoteles 3* & 58.383 & 51.570 & $-13,18 \%$ & 50.691 & $-1,70 \%$ \\
Hoteles 1 y 2* & 31.196 & 28.778 & $-8,08 \%$ & 28.675 & $-0,36 \%$ \\
Hostales, albergues y pensiones & 35.062 & 34.487 & $11,31 \%$ & 39.028 & $13,17 \%$ \\
Casas rurales & 9.775 & 12.886 & $46,10 \%$ & 14.281 & $10,83 \%$ \\
Apartamentos & 61.833 & 68.376 & $15,85 \%$ & 71.634 & $4,76 \%$ \\
VFT & - & - & & 167.923 & \\
Total & 359790 & 365579 & $1,61 \%$ & 540833 & $26,18 \%$ \\
\hline
\end{tabular}

Fuente: elaboración propia a partir de datos del INE.

Se pueden extraer una serie de conclusiones del análisis expuesto. En primer lugar, cabe destacar que la tarta del turismo está creciendo en Andalucía en los últimos años. La inestabilidad política de Oriente Medio y de otras zonas de gran afluencia turística como Cataluña está coadyuvando a que Andalucía se esté convirtiendo en una región más atractiva para los turistas.

En segundo lugar, y como consecuencia de lo anterior, se puede apreciar cómo, sin la irrupción de las VFT, Andalucía se vería en dificultades para absorber el crecimiento de la demanda de plazas de alojamiento que se está desplegando. Como ilustra la Tabla 2, las pernoctaciones están creciendo en todas las categorías de alojamiento, por lo que, de momento, puede concluirse que las VFT y los hoteles ofrecen servicios cualitativamente distintos (al menos los de 4 y 5 estrellas) y que son, en cierta medida, complementarios.

Finalmente, cabe matizar dicha complementariedad. Atendiendo a los datos de la Tabla 4, parece que son los hoteles de 3 estrellas para abajo los que más están sufriendo la competencia de las VFT. Esto se ve reflejado en la disminución del número de plazas ofertadas. La reestructuración del sector parece que irá precisamente hacia un modelo de hoteles de alta categoría (4 y 5 estrellas), que convivirá con las VFT y, en menor medida, con hoteles de inferior categoría, que van cediendo terreno, tanto a las VFT como los hostales, albergues y pensiones.

\subsubsection{El Decreto andaluz de viviendas con fines turísticos}

En lo que al análisis de la regulación se refiere, la modificación de la LAU a la que se ha hecho referencia, y la consiguiente adaptación, se materializó en el Decreto 28/2016 de las Viviendas con Fines Turísticos. Los requisitos de acceso y ejercicio para ejercer esta actividad se encuentran exclusivamente en esta norma. Asimismo, la norma es fruto de la labor coordinada de la administración de la Junta de Andalucía. La Agencia de Defensa de la Competencia de Andalucía (en adelante, ADCA) participó en el proceso de elaboración de esa norma y la mayor parte de sus recomendaciones fueron aceptadas.

En concreto, la ADCA, en función de sus competencias, elaboró un informe del Proyecto de Decreto de las VFT. En esta sección se presentan, a grandes rasgos, los resultados 
del informe realizado por la $\mathrm{ADCA}^{27}$. En este sentido, se partió de análisis previos sobre la mejora de la regulación económica. Es decir, sobre si la legislación vigente establece o no restricciones innecesarias o desproporcionadas para ejercer la actividad económica en cuestión. De este modo, la mejora de la regulación económica en el sector del alojamiento ha de permitir la creación de un level playing field que establezca un marco de competencia efectiva, tanto para los operadores establecidos del modelo tradicional como para aquéllos del emergente colaborativo.

Asimismo, el informe destacó el impacto económico positivo de la propuesta de norma, debido a la dinámica en expansión que presenta el sector y que dicho auge ha estado protagonizado fundamentalmente por la demanda extranjera. Por lo que se refiere al impacto directo en el empleo, el sector no genera un volumen específico importante. No obstante, se debe valorar su efecto de arrastre sobre otros sectores que se concentra, principalmente, en comercios y hostelería de proximidad; lo cual repercute positivamente en la capacidad de generación de actividad económica y empleo.

Estos elementos permiten valorar de forma muy positiva el papel que desempeña el alquiler de VFT como elemento de desarrollo en el ámbito local y también la necesidad de dotar al sector de una regulación eficiente y favorecedora de la competencia, y concluía el análisis económico en que no se debe cerrar este mercado con una regulación restrictiva.

En lo que respecta al análisis del mercado, el Decreto de las VFT establece a grandes rasgos una delimitación del mismo atendiendo a dos criterios. En primer lugar, la duración del contrato. Se establece el margen en contratos que no superen los dos meses computados de forma continuada por una misma persona usuaria. Así, nos encontramos ante dos mercados claramente diferenciados:

- Servicio de hospedaje turístico, al que se le aplica el citado Decreto y que, por tanto, deben ser considerados como operadores económicos.

- Mercado de alquiler “clásico” de viviendas regulados por la LAU.

En segundo lugar, el volumen de plazas o viviendas ofertadas:

- Micro-operadores, cuando el oferente presta el servicio de alquiler o de una o dos viviendas, a los que se les aplica una menor carga reguladora.

- Operadores turísticos "profesionales", que ofertan tres o más viviendas. Se les aplicaría el régimen previsto para los apartamentos turísticos no contiguos.

Esta delimitación se entendía ajustada a una regulación eficiente y favorecedora de la competencia y, por tanto, en este aspecto el Decreto permitiría atender a los elementos característicos de los distintos operadores del sector.

Por lo que respecta a los resultados en términos de regulación económica eficiente, cabe señalar que, en líneas generales, el objetivo del Decreto se ha cumplido:

- En la medida en que se ordena, en el territorio andaluz, las VFT como un servicio de alojamiento turístico, especialmente para micro-operadores; a los que se les aplica una menor carga reguladora, básicamente la presentación de una "Declaración Responsable" que permite ejercer la actividad.

\footnotetext{
${ }^{27}$ Informe ${ }^{\mathrm{o}} 11 / 2015$.
} 
- Se dan garantías en relación a la facturación y los cobros para las personas usuarias de viviendas turísticas, así como sobre el precio y anticipos; la formalización del contrato; el acceso y condiciones de la vivienda; y la reserva y su posible cancelación.

Desde la entrada en vigor del Decreto 28/2016, más de 35.000 viviendas con fines turísticos han presentado su declaración responsable para el inicio de la actividad; lo que supone un total de más de 160.000 plazas de alojamiento.

Por otra parte, este Decreto ha evitado a la Comunidad Autónoma de Andalucía una serie de conflictos, especialmente con la CNMC y la normativa de unidad de mercado, tal y como se están sucediendo en otras Comunidades Autónomas (Madrid, Cataluña, Canarias, Baleares y Galicia), como veremos en el siguiente apartado.

Ante esta situación, se puede concluir que el Decreto 28/2016 puede ser un ejemplo de regulación económica eficiente para este sector.

A pesar de ello, cabe recordar que las normas no son perfectas y el proceso de mejora de la regulación económica es una labor permanente. A este respecto, la ADCA ha iniciado una línea de investigación sobre el fenómeno de las VFT en Andalucia que abarca:

$\Rightarrow$ Una caracterización de la oferta de VFT en Andalucía

$\Rightarrow$ Un análisis comparativo de las distintas regulaciones de las VFT en otras CCAA y en otros países de la UE, para identificar las mejores prácticas.

$\Rightarrow$ Un análisis de sustituibilidad/complementariedad del servicio ofrecido por el alojamiento tradicional y el nuevo modelo VFT.

$\Rightarrow$ Un estudio de impacto económico del mercado de las VFT en Andalucía

$\Rightarrow$ Un estudio de los sistemas de valoración/ reputación; el modo en que estos podrían ser protegidos de manipulaciones para que la información sea lo más perfecta posible.

En definitiva, de lo que se trata es de emprender un nuevo análisis, esta vez sobre los efectos del Decreto 28/2016. Posteriormente, un informe recogerá el pronunciamiento de este organismo sobre los aspectos económicos señalados $\mathrm{y}$, en su caso, sobre las posibles deficiencias en la regulación detectadas y las recomendaciones de mejora.

\subsection{Iniciativas reguladoras autonómicas sobre viviendas turísticas}

A continuación se van a exponer de un modo sintético los resultados del un estudio comparativo sobre los intentos por establecer marcos reguladores en el mercado del alojamiento turístico por parte de distintos gobiernos autonómicos. Por coherencia, se han incluido los casos de las Comunidades Autónomas donde el turismo (y por ende el mercado del alojamiento) tienen una mayor relevancia. Éstas son Islas Baleares, Cataluña, Madrid, Canarias, Valencia (no se incluye en los resultados puesto que su normativa se encuentra en proceso de revisión) y Galicia. Para completar el análisis se incluyen dos Comunidades Autónomas (Castilla y León y Aragón) en las que el turismo no tiene tanto peso en términos económicos, pero que sirven para dibujar el estado de la cuestión en el Estado español. Los resultados se presentan en orden cronológico. 
Tabla 5. Resultados del estudio comparativo sobre iniciativas reguladoras autonómicas en el mercado de las VFT.

\begin{tabular}{|c|c|c|}
\hline CCAA & $\begin{array}{l}\text { INSTRUMENTO } \\
\text { LEGISLATIVO } \\
\end{array}$ & OBSTÁCULOS A LA COMPETENCIA \\
\hline $\begin{array}{l}\text { COMUNIDAD } \\
\text { DE MADRID }\end{array}$ & $\begin{array}{l}\text { Decreto } 79 / 2014 \text {, de } 19 \text { de julio, } \\
\text { por el que se regulan los } \\
\text { apartamentos turísticos }\end{array}$ & $\begin{array}{l}\text { Establece un límite temporal al alquiler de la vivienda turística, } \\
\text { exigiendo que éste no sea inferior a } 5 \text { días. }\end{array}$ \\
\hline CANARIAS & $\begin{array}{l}\text { Decreto } 113 / 2015 \text {, de } 22 \text { de } \\
\text { mayo, por el que se aprueba el } \\
\text { Reglamento de las viviendas } \\
\text { vacacionales de la Comunidad } \\
\text { Autónoma de Canarias }\end{array}$ & $\begin{array}{l}\text { 1) Prohíbe que las viviendas vacacionales se establezcan en zonas } \\
\text { turísticas; o donde se localicen hoteles y apartamentos. } \\
\text { 2) Prohíbe el alquiler de habitaciones de forma separada. } \\
\text { 3) Exige una declaración responsable supeditada a la inscripción en un } \\
\text { registro. }\end{array}$ \\
\hline GALICIA & $\begin{array}{l}\text { Decreto } 12 / 17 \text {, de } 26 \text { de enero, } \\
\text { por el que se establece la } \\
\text { ordenación de apartamentos } \\
\text { turísticos, viviendas turísticas y } \\
\text { viviendas de uso turístico en la } \\
\text { Comunidad Autónoma de Galicia }\end{array}$ & $\begin{array}{l}\text { Respecto a los apartamentos y viviendas turísticas: } \\
\text { 1) Prohíbe el alquiler por habitaciones y limita el período de } \\
\text { alojamiento a tres meses. } \\
\text { 2) Subordina el acceso a la actividad a un régimen de declaración } \\
\text { responsable con características más propias de una autorización } \\
\text { administrativa. } \\
\text { 3) Presenta un catálogo exagerado de requisitos técnicos y servicios } \\
\text { mínimos exigidos. } \\
\text { Respecto a las viviendas de uso turístico: } \\
\text { 1) Permite que los ayuntamientos limiten el número de viviendas (o } \\
\text { incluso las prohíba) en determinados edificios o sectores urbanísticos. } \\
\text { 2) Prohíbe la cesión por habitaciones. } \\
\text { 3) Establece un régimen jurídico diferenciado en función de elementos } \\
\text { temporales no justificados. } \\
\text { 4) Régimen de acceso a la actividad muy agravado con cargas } \\
\text { adicionales desproporcionadas. } \\
\text { 5) Catálogo de requisitos y servicios mínimos excesivos. }\end{array}$ \\
\hline $\begin{array}{l}\text { CASTILLA Y } \\
\text { LEÓN }\end{array}$ & $\begin{array}{l}\text { Decreto } 3 / 17 \text {, de } 16 \text { de febrero, } \\
\text { por el que se regulan los } \\
\text { establecimientos de alojamiento } \\
\text { en la modalidad de vivienda de } \\
\text { uso turístico en la Comunidad de } \\
\text { Castilla y León }\end{array}$ & $\begin{array}{l}\text { 1) Inclusión, con carácter orientativo, de los precios de los } \\
\text { alojamientos en catálogos, directorios guías o sistemas informáticos. } \\
\text { 2) Catálogo exagerado de requisitos técnicos y servicios mínimos } \\
\text { exigidos. } \\
\text { 3) Exige que la vivienda tenga un distintivo y la asistencia telefónica } \\
24 \text { horas. } \\
\text { 4) Prohíbe la cesión por habitaciones. } \\
\text { 5) Establece un régimen jurídico diferenciado en función de elementos } \\
\text { temporales de la estancia y la actividad. }\end{array}$ \\
\hline $\begin{array}{l}\text { ISLAS } \\
\text { BALEARES }\end{array}$ & $\begin{array}{l}\text { Ley } 6 / 2017 \text {, de } 31 \text { de julio, de } \\
\text { modificación de la Ley } 8 / 2012, \text { de } \\
19 \text { de julio, relativa a la } \\
\text { comercialización de estancias } \\
\text { turísticas en viviendas }\end{array}$ & $\begin{array}{l}\text { 1) Establece un límite al número de plazas turísticas en alojamientos } \\
\text { turísticos y a las plazas objeto de comercialización turística en } \\
\text { viviendas de uso residencial. } \\
\text { 2) Delimitación de zonas aptas para poder llevar a cabo la } \\
\text { comercialización turística. } \\
\text { 3) Establece la posibilidad de prohibición en los estatutos de la } \\
\text { propiedad horizontal. }\end{array}$ \\
\hline CATALUÑA & $\begin{array}{l}\text { Plan Especial Urbanístico de } \\
\text { Alojamientos Turísticos (PEUAT) }\end{array}$ & $\begin{array}{l}\text { Exige que la estancia de las personas alojadas en residencias y colegios } \\
\text { mayores no sea inferior a } 30 \text { días. }\end{array}$ \\
\hline ARAGÓN & $\begin{array}{l}\text { Proyecto de Decreto sobre } \\
\text { viviendas de uso turístico en } \\
\text { Aragón }\end{array}$ & $\begin{array}{l}\text { 1) Limitación temporal: la estancia no podrá ser superior a un mes. } \\
\text { 2) Prohibición de la cesión por habitaciones. } \\
\text { 3) Exigencia de identificación de las viviendas. } \\
\text { 4) Otros requisitos desproporcionados relacionados con la capacidad }\end{array}$ \\
\hline
\end{tabular}


Fuente: elaboración propia.

Como puede apreciarse en la Tabla 5, muchas han sido las restricciones desproporcionadas o injustificadas que los organismos reguladores autonómicos han intentado establecer en el mercado de las VFT. Esta actitud de relativa hostilidad hacia el emergente modelo del alojamiento colaborativo, cuyas virtudes han sido subrayadas a lo largo del presente trabajo, lleva a pensar que pueden estar dándose situaciones de captura del regulador. Las barreras identificadas a través de nuestro estudio comparativo no parecen beneficiar al interés general, sino a los operadores establecidos.

Una segunda lección extraída de nuestro estudio es que varias de las restricciones son recurrentes; es decir, se replican en diferentes marcos reguladores autonómicos. Entre ellas se encuentran:

a) La limitación temporal, ya sea estableciendo períodos máximos de estancia (como en Aragón, un mes) o estancias mínimas (como en Madrid, 5 días; o en Cataluña, 30 días).

b) La prohibición de alquilar habitaciones de forma separada (Canarias, Galicia, Castilla y León y Aragón).

c) Procedimientos de declaración responsable que la asemejan a la figura de la autorización (Galicia y Canarias).

d) Zonas libres de VFT (Canarias, Galicia e Islas Baleares).

\section{CONCLUSIONES}

El rápido desarrollo de la economía colaborativa está cambiando las estructuras de ciertos mercados. El transporte y el alojamiento son dos de los sectores que más están siendo interpelados por un nuevo modelo de producción y consumo basado en las nuevas tecnologías de la información y la comunicación, que permite el intercambio de información en tiempo real, pone en valor activos infrautilizados y cuenta con un sistema de valoración/reputación que permite que los usuarios cuenten con mejor información antes de acceder al bien o servicio en cuestión. Todo ello redunda en la eficiencia económica y el bienestar del consumidor.

Si bien la economía colaborativa guarda un fuerte potencial para impulsar el crecimiento económico, no es menos cierto que se trata de un fenómeno que plantea importantes retos de regulación. En este sentido, la regulación que se configure debe establecer un marco de competencia efectiva entre los operadores tradicionales y los emergentes colaborativos. No se trata de favorecer la salida de los primeros, ni de fomentar o impedir la entrada de los segundos, sino de que la propia dinámica del mercado, como mejor mecanismo conocido de asignación de recursos, configure la estructura del mismo en función de las preferencias de los consumidores.

El estudio de los proyectos de regulación autonómicos que se han tratado de establecer en el Estado español en los últimos años, muestra que los organismos reguladores se han visto tentados a proteger los intereses de los operadores establecidos, imponiendo restricciones y cargas desproporcionadas o innecesarias a los nuevos entrantes. Andalucía es la excepción que confirma la regla, donde la regulación permite que los micro-operadores penetren en el mercado sin más cargas que la mera presentación de una declaración responsable, 
posibilitando que los beneficios de la economía colaborativa se vayan materializando. Por ello, el Decreto andaluz puede considerarse como ejemplo de regulación económica eficiente.

Sin embargo, el proceso de mejora de la regulación económica es una labor permanente, y la regulación andaluza no es perfecta. Por ello, será necesario continuar con el estudio y análisis del desarrollo del mercado del alojamiento colaborativo para adaptar la regulación a la dimensión del mismo. Cuestiones como la posición de dominio de las plataformas, la fiscalidad, la manipulación de los sistemas de valoración y el impacto económico de este nuevo mercado deberán ser abordadas para garantizar una regulación económica eficiente en un sector fundamental para el crecimiento económico de los próximos años. 


\section{BIBLIOGRAFÍA}

\section{RECURSOS BIBLIOGRÁFICOS}

Bardhi, F. y Eckhardt, G. M. (2012): "Acces-based consumption: the case of car sharing", Journal of consumer research, vol. 39, nº, pp. 81-98.

Belk, R. (2014): "You are what you can access. Sharing and collaborative consumption online", Journal of Business Research, vol. 67, nº, pp. 1595- 1600.

Coase, R. (1937): “The nature of the firm”, Economica, New Series, Vol. 4, No. 16. (Nov., 1937), pp. 386-405.

Cohen, M. y Sundararahan, A. (2015): "Self -regulation and innovation in the Peer-to-Peer sharing economy", The University of Chicago Law Review Dialogue, vol. 82, pp. 116133.

Demary, V. (2015): “Competition in the Sharing Economy", IW policy paper 19/2015, Cologne Institute for Economic Research.

Edelman, B. G. y Gerardin, D. (2016): "Efficiencies and regulatory shortcuts: how should we regulate companies like Airbnb or Uber?” Stanford Technology Law Review, n¹9, pp. 293-328.

Evans, D. S. y Schamalensee, R. (2016): Matchmakers. The new economics of multisided platforms, Harvard Business Review Press, Boston.

Fernández Durán, R. y González Reyes, L. (2015): En la espiral de la energía, Libros en Acción.

Franch Fluxá, J. y Ribas Conrado, J. F. (2013): "El alquiler de viviendas para uso vacacional. Perspectiva actual, problemas y propuestas legales", Estudios turísticos, nº195, pp. 3557.

Gerardin, D. (2015): "Uber and the rule of law: Should spontaneous liberalization be applauded or criticized? Competition Policy International, vol. 11, $\mathrm{n}^{\mathrm{o}} 1$.

Guillén Navarro, N. e Íñiguez Barrozpe, T. (2016): “Acción pública y consumo colaborativo. Regulación de las viviendas de uso turístico en el contexto p2p", Pasos, Revista de Turismo y Patrimonio Cultural, vol. 14, $n^{\circ} 3$. Special Issue, pp. 751-768.

Goudin, P. (2016): "The cost of non Europe sharing economy", European Parliament Research Service.

Jefferson-Jones, J. (2016): "Airbnb and the housing segment of the modern sharing economy: Are short-term rental restrictions an unconstitutional taking?" Hasting Constitutional Law Quarterly, n³, pp. 457-576.

Katz, V. (2015): "Regulating the sharing economy", Berkeley Technology Law Journal, vol. $30, n^{\circ} 4$.

Koopman et al. (2015): "The sharing economy and consumer protection regulation. The case for policy change", Journal of business, entrepreneurship and the law, vol. 8, $\mathrm{n}^{\circ} 2$, pp. 529-545. 
Lora-Tamayo Vallvé, M. (2017): "Economía colaborativa y alojamiento", en Montero Pascual (2017), pp. 283-325.

Lougher, G. y Kalmanowicz, S. (2016): "EU Competition Law in the sharing economy", Journal of European Competition Law and Practice, vol. 7, n² 2, pp. 87-102.

Mandel, E. (1975): Introducción a la Economía Marxista, Editorial Nova Terra.

Montero Pascual, J. J. (2017): La Regulación de la Economía Colaborativa, Monografías Tirant lo Blanch.

Montero Pascual, J. J. (2017): "La Regulación de la Economía Colaborativa", en Montero Pascual (2017), pp. 23-64.

Oskam, J. y Boswijk, A. (2016): "Airbnb: the future of networked hospitality businesses, Journal of Tourism Features, vol. 2, nº1, pp. 22-42.

Rifkin, J. (2014): La sociedad de coste marginal cero, Paidos.

Rochet, J.C. y Tirole, J. (2003): "Platform competition in two side markets", Journal of the European Economic Association, vol. 1 n4, pp. 990-1090.

Smorto, G. (2016): "The case for regulating the sharing economy", Workshop on Collaborative Economy. European Parliament. Brussels.

Sundararahan, A. (2016): Sharing Economy: The End of Employment and the Rise of CrowdBased Capitalism, The MIT Press, Cambridge, London.

Stoke, C. et al. (2014): "Making Sense of the UK Collaborative Economy", NESTA Collaborative Lab, London.

Rochet, J. C. y Tirole, J.: "Platform competition in two side markets", Journal of European Economic Association, vol.1, número 4, 2003, pp. 990- 1029.

\section{FUENTES DOCUMENTALES}

CNCM (2017): Informe de 28 de abril de 2017 sobre la reclamación presentada, al amparo del artículo 26 de la ley 20/2013, de 9 de diciembre, de garantía de la unidad de mercado, contra la imposición de un plazo mínimo de alojamiento a las residencias de estudiantes (um/064/17).

Comisión Nacional de los Mercados y la Competencia (CNMC) (2016): "Estudio sobre los nuevos modelos de prestación de servicios y la economía colaborativa. Resultados preliminares", E/CNMC/004/15, disponible en: https://www.bez.es/images/carpeta_gestor/archivos/RESULTADOS PRELIMINARES. pdf, página consultada el 22.10.2017.

Comisión de Mercado Interior y Protección del Consumidor (2017): "Sobre una Agenda Europea para la economía colaborativa”, (2016/0000(INI)), 11.5.2017.

Comisión Europea (2016): Comunicación de la Comisión al Parlamento Europeo, al Consejo, al Comité Económico y Social Europeo y al Comité de las Regiones: "Una Agenda Europea para la economía colaborativa”, SWD (2016) 184 final. Bruselas, 2. 6. 2016. 
Decreto 28/2016, de 2 de febrero, de las viviendas con fines turísticos y de modificación del Decreto 194/2010, de 20 de abril, de establecimientos de apartamentos turísticos de Andalucía.

Decreto 3/2017, de 16 de febrero, por el que se regulan los establecimientos de alojamiento en la modalidad de vivienda de uso turístico en la Comunidad de Castilla y León. Boletín Oficial de Castilla y León, pp. 5125-5142.

Diario Sur, 27 de octubre de 2017, disponible en: http://www.diariosur.es/turismo/plazasviviendas-turisticas-20171027224225-nt.html, página consultada el 31.10.2017

Exceltur, PIB y empleo turístico por Comunidades Autónomas, disponible en: https://www.exceltur.org/pib-y-empleo-turistico-por-c-c-a-a/, página consultada el 10.10.2017.

Ley 15/2007, de 3 de julio, de Defensa de la Competencia. BOE núm. 159, de 4 de julio de 2007. Referencia: BOE-A-2007-12946.

Oxera (2015): "A fair share? The economics of the sharing economy", Oxera Agenda.

PWC (2016): "Assessing the size and presence of the collaborative economy in Europe", disponible en: https://www.pwc.es/es/publicaciones/transformacion-digital/evaluacioneconomia-colaborativa-europa.html, página consultada el 18.07.2017. 